\title{
A Rough Variant of Nontoxigenic Vibrio Cholerae 0139 Imported From Vietnam
}

\section{Pontus Westerström ( $\nabla$ ponwe@me.com )}

Nordsjællands Hospital

\section{Ulrik Bak Dragsted}

Nordsjællands Hospital

\section{Research Article}

Keywords: Vibrio cholerae, cholera, 0139, non-01/non-0139, horizontal gene transfer, lateral gene transfer, virulence factors, evolution

Posted Date: December 6th, 2021

DOI: https://doi.org/10.21203/rs.3.rs-1077982/v1

License: (1) This work is licensed under a Creative Commons Attribution 4.0 International License. Read Full License 


\section{Abstract}

Purpose (stating the main purposes and research question)

Vibrio cholerae is classified in 0-antigen polysaccharide outer membrane properties where 01 and 0139 are strains that cause pandemics and epidemics while non-01/non-0139 usually cause mild disease. The dynamic evolution of Vibrio cholerae involves new virulence factors through horizontal gene transfer and formerly nontoxigenic serogroups are being reported as causing increasingly severe forms of human disease. Our purpose was to investigate serogroup and virulence factors in one imported isolate from Vietnam and compare these to virulence factors seen in different strains of Vibrio cholerae.

Methods

We have serotyped one isolate of imported Vibrio cholerae from Vietnam to Denmark and performed whole genome sequencing to identify known virulence genes.

Results

We have identified virulence factors in our isolate that are recently discovered and one toxin, MakA, has not previously been reported from an Asian strain. The isolate was found to be a serogroup non-01/non0139 strain, however, sequence analysis gave a 96, 6\% ID match of the $w b f Z$ gene, stipulating our isolate to belong to either serogroup 022 or 0139.

Conclusions

Looking at the combination of virulence factors of the isolate we suggest the finding of a rough variant of a nontoxigenic Vibrio cholerae 0139 rather than a 022 serogroup version. This is a rare finding in a clinical isolate.

\section{Introduction}

Vibrio cholerae belongs to the family Vibrionaceae which naturally inhabits the marine and riverine microbiota (1-3). It is a motile gram-negative rod which was first described and named by Italian anatomist Filipo Pacini in 1854 (4), although the London-based physician John Snow, in a pamphlet published in 1849, preceded Pacini in arguing the theory of fecal contamination of water (5). Later, in 1883 , Robert Koch isolated and detected the "Kommabacillus" using microscopy during an epidemic of cholera in Egypt, thus presenting evidence of the microbiological pathophysiology. The Vibrio cholerae serogroups were classified during the 1930's from outer membrane 0-antigen polysaccharide composition and currently there are 206 known serogroups (6-9). There are two 01 biotypes; classical" or El Tor and three distinct serotypes named Ogawa, Inaba and Hikojima. The El Tor has properties in producing hemolysins and is the major cause of the current 7th cholera pandemic which emerged in Indonesia in 1961. The name El Tor derives from a quarantine camp in the Sinai desert, along the pilgrimage pathway from Mecca; the camp was initiated after the 19th century pandemics of cholera and 
this is where the causative 01 hemolytic strain El Tor was first publicly reported on in 1906, although previously observed in 1897 in the Middle East (10-14).

The virulence of Vibrio cholerae has been extensively investigated, and dates back as far as 1884 when Robert Koch first suggested evidence of a cholera toxin, but the toxin was not proven until 1959 (15-17). The pathophysiology in cholera watery diarrhea is explained by an altered permeability of small intestine epithelial cells caused by the cholera toxin which together with the colonising factor toxin-coregulated pilus (Tcp) represents the two major components of Vibrio cholerae virulence (18-19). The exotoxin induces osmotic loss of fluid and electrolytes resulting in a rapidly progressing dehydration. The serogroups of Vibrio cholerae have traditionally been divided into toxigenic (01 serogroup) and nontoxigenic (non-01 serogroup), but in late 1992 a formerly unknown serogroup was identified during a cholera-like diarrhea outbreak in Bangladesh and India (20-21). This new serogroup, named 0139 Bengal, was a potent cause of human disease and presented with different genetic composition and phenotype features than $01 \mathrm{El}$ Tor. The 0139 Bengal was the result of a mutation, substituting the $22 \mathrm{~kb}$ $\mathrm{rfb}$ region in 01 with a $35 \mathrm{~kb}$ region of DNA encoding the surface polysacharide.(22). An altered variant named 0139 Calcutta was later reported from an outbreak in 1996 (25-26). To this date the classification of serogroups 01/0139 and non-01/non-0139 has stayed unchanged in the continuous 7th cholera pandemic. The evolutionary pathway of the 7th pandemic originates in the Bay of Bengal, with an estuarine aquatic environment which has made possible for Vibrio cholerae to genetically evolve into novel subtypes potentially harmful to humans (27). One hypothesis is that the Vibrio cholerae progenitor has acquired new characteristics by horizontal gene transfer, a way for genetic material to be passed "sideways", also to relatively unrelated species rather than to a descendant, having introduced several genomic islands (ie VPI-1, VPI-2 and GI-1 to GI-10, TLC) to become 01 and then additionally CTX and RS1 to further evolve into $01 \mathrm{El}$ Tor and 0139 strains. $(23,27)$ (Figure 1).

Most Vibrio cholerae serotypes are nonpathogenic but present with an extreme genomic plasticity which allows evolution of persistent heterogenous strains with a clonal intensity shifting with environmental salinity, temperature and suggested seasonal algal blooms (28). Non-01/non-0139 strains do not normally possess the virulence factor(s) blocking host inflammation and consequently, when they cause human disease, occurrence of invasive bacteraemia is a more frequent finding. The common clinical findings in non-01/non-0139 infections include gastroenteritis, wound infections, external otitis and bacteraemia (29). The non-01/non-0139 were traditionally considered as nontoxigenic but have reportedly become commonly causative to both sporadic cases of human disease and smaller outbreaks of cholera (30-32). Recent studies of the evolutionary development show that horizontal gene transfer of virulence factors, not only within the Vibrionaceae family, but also from neighboring species such as Pseudomonas aeruginosa, Haemophilus somnus, Vibrio vulnificus and Haemophilus influenzae contributes to the genetic diversity in non-01/non-0139 Vibrio cholerae (33). A major concern regarding non-01/non-0139 strains is the development of resistance to antibiotics since antibiotics is a critical element of treatment of invasive disease in contrast to fluid and electrolyte resuscitation in cholera epidemics (34-35). 
We report on a previously healthy person in the mid-60's who developed severe gastroenteritis upon returning to Denmark from Vietnam after a three-week vacation.

All accommodations were at high standards and he reported sole intake of bottled water, but food taken from street kitchens. He had no history of soft tissue wounds and no contact to animals. Prior to the departure to Vietnam the patient had a Di-Te booster, HAV and HBV vaccinations. The patient had a history of hypertension. During the return flight to Denmark the patient developed watery diarrhea and over the following six days he had bowel movements up to 30 times daily. Even though the patient tried to compensate the loss of fluid, he was feeling increasingly unwell, had abdominal pains and on the 4th day after arrival to Denmark he contacted his general practitioner (GP). The GP sent stool cultures for analysis which grew Vibrio cholerae and the patient was referred to the Department of Pulmonary and Infectious Diseases at the local teaching hospital. The patient had a normal physical examination. Blood tests showed slightly low potassium $(3,3 \mathrm{~mol} / \mathrm{L}$; reference range $3,5-4,4 \mathrm{mmol} / \mathrm{L})$ and signs of dehydration with, creatinine $137 \mu \mathrm{mol} / \mathrm{L}$ (reference range, male over 18 years; 60 - $105 \mu \mathrm{mol} / \mathrm{L}$ ) and urea $8,7 \mu \mathrm{mol} / \mathrm{L}$ (reference range, male over 50 years; $3,5-8,1 \mathrm{mmol} / \mathrm{L}$ ). A stool sample was analysed using a Point-of-Care Test (FilmArray ${ }^{\circledR}$ Gastrointestnal panel, Biomérieux) with identification of Vibrio cholerae and enteroaggregative $E$. coli (EAEC). The same sample sent for routine stool culture at the local Microbiology Department grew only Vibrio cholerae. Further analysis at the national reference laboratory at Statens Serum Institut (SSI) demonstrated a non-01/non-0139 serogroup. Prior to the results of the stool analysis the patient was prescribed oral metronidazole by the GP, which at the hospital was changed to a single dose of $1 \mathrm{~g}$ of azithromycin. The patient also received 2 litres of iv SodiumPotassium-Glucose fluid after which he quickly recovered from his diarrhea. He was discharged 16 hours after arrival to the hospital with Potassium-Chloride tablet treatment for xx days.

\section{Methods}

Data reported to SSI and Vibrio strain analysis performed at SSI was extracted from archives, for the years 2004 - 2019. Our reported isolate was tested at the North Zealand hospital using POCT procedures with BD FecalSwab TM (Copan Italia SpA) and PCR analysed in The Film Array GI Panel (BioFire Diagnostics, Biomeriux, Salt Lake City, Utah). The stool sample was routinely sent to the microbiological laboratory at Herlev University Hospital for cultivation and upon growth of Vibrio cholerae the pure culture was forwarded to SSI for serotyping for national surveillance. Serotyping was performed using 01 and 0139 Vibrio cholerae specific antisera (Denka Seiken, Tokyo, Japan). The isolate was also subject to whole genome sequencing (WGS) using the Illumina NextSeq and WGS data analysed for the presence of virulence genes using the CholeraeFinder webtool located at the Center for Genomic Epidemiology (https://cge.cbs.dtu.dk/services/CholeraeFinder/) with 95\% ID and min. 60\% gene length). The Multilocus sequence typing (MLST) was assigned using the webtool MLST 2.0 (https://cge.cbs.dtu.dk/services/MLST/).

\section{Results}


Denmark has a centralised mandatory clinical and microbiological reporting system for a list of pathogens and infections including cholera. Reporting is done to the SSI where only 25 cases have been registered from 2004 to 2019. Over the years 2004-2012 isolates were only tested for subtype 01 and from 2013 for both subtype 01 and 0139. Analysis of all isolates sent to SSI found two serogroup 01 and 23 cases of non-01/non-0139 isolates.

Serotyping of the analysed isolate was performed and was subsequently classified as Vibrio cholerae non-01/non-0139. The sequence data revealed sequence type (ST) 558 and a match to the $0139 \mathrm{wbfZ}$ gene variant with $96,6 \%$ ID. The isolate possessed the virulence genes: makA, hlyA, toxR, rtxA and als. Furthermore, markers from the genetic islands VSP-2 and VPI-2 were detected. No acquired resistance genes were present in the strain, while a ParC gene variant encoding a mutated topoisomerase IV subunit A (resistance to quinolone) was found.

\section{Discussion}

In recent years a modernised and rapid alternative to laboratory cultivation has been introduced in the infectious medicine clinician's daily work. The point-of-care-test (POCT) simplifies diagnostics on molecular test arrays (36-37). At the North Zealand hospital Emergency Unit we have introduced routine use of POCT for common infectious diseases such as influenza, RS virus and gastrointestinal disease. The point-of-care-test we use offers analysis of 22 bacteria, viruses and parasites with high sensitivity $(98,5 \%)$ and specificity $(99,2 \%)(38)$. Given the rare finding of an imported case of Vibrio cholerae from Vietnam to Denmark we decided to analyse the isolate and characterise its genetic and virulence properties.

Since the evolutional change of $01 \mathrm{El}$ Tor in late 1992 into the new Vibrio cholerae serogroup 0139 Bengal the cholera epidemic has persisted and spread in Asia. The 0139 Bengal had acquired new genetic properties by a deletion of the wbe region of 01 and an insertion of the region $w b f$ encoding the 0139 0-antigen, involving homologous recombination or a suggested horizontal gene transfer from a non-01/non-0139 strain (022) (32, 39-42). The new 0139 Bengal largely resembled the $01 \mathrm{El}$ Tor but due to absent immunity in the population the new 0139 Bengal infected susceptible adults rather than children, which $01 \mathrm{El}$ Tor used to do (42). Over the years 1993-95 there was a local predominance of the 0139 Bengal in reported cases of cholera disease in Bangladesh and parts of India, until a new clone of $01 \mathrm{El}$ Tor reemerged. The two strains 01/0139 are now responsible for the ongoing cholera epidemic in Asia, still globally referred to as the 7 th pandemic of cholera $(41,43)$.

Our initial serotyping into a non-01/non-0139 serogroup was questioned when the WGS came out with a $96,6 \%$ match on the serogroup 0139 gene $w b f Z$. There are previously reported rough variants of the 01/0139 serogroups which present as 01/0139 on PCR analysis but lack the 01/0139 surface antigen and thus fail to agglutinate 01/0139 antisera; the analysed isolate suggesting a rough variant of nontoxigenic 0139 (31). However, there is also reported misidentification due to cross-agglutination with commercial 0139 antisera due to related 0 antigens in 0139, 0155 and 022 serogroups (44). The rough 
variants are hypothesised to represent strains which are more prone to genetic change as they are commonly seen on epidemiological and surveillance data during periods preceding a change in serogroup, from Inaba to Ogawa or vice versa (45). The absence of the expected major virulence factors CTX and toxin-coregulated pilus (TcP) is previously presented as unconventional 0139 nontoxigenic strains, reported in two publications from 2019; a Shanghai study of clinical cases from the 7th pandemic and in a genetic analysis of four 0139 strains from Bangladesh (46-47). The Vibrio Seventh Pandemic islands (VSP-1 and VSP-2) is a gene cluster identified in the 7th pandemic El Tor strains which is found absent in classical and pre-7th pandemic strains (48-49). The VSP-1 and VSP-2 are occasionally seen in non-01/non-0139 strains but rarely together $(31,50)$. The role of VSP islands remains unestablished but are suggested to provide increased environmental fitness to those strains carrying the genes (50). VSP-2-like elements which have similar ORFs (Open Reading Frame) in noncholera Vibrios indicate that they have a natural environment function (51). Recent genetic analysis has revealed VSP-2 subgroups with various geographical origins making it a tool in analysing genetic lineages of global cholera transmission (52). The analysed isolate possessed a complete VSP-2 and 86, $9 \%$ of VSP-1. The common finding of incomplete VSP islands in environmental strains may represent either precursors that are intermediates in the process of clustering into functional VSP islands or the result from gene deletion events (53). The $h l y A$, rtxA and toxR are commonly found in both 01/0139 and non-01/non-0139 strains $(31,48)$. The absence of CTX and Tcp in the analysed isolate indicate the known potency of other virulence factors, some which are recently described and not fully understood in mechanism. The Multifunctional Autoprocessing Repeats-in-Toxins (MARTX/RtxA) is considered to contribute significantly to the pathogenesis and cytotoxicity of Vibrio cholerae and is present in nearly all strains (54). The analysed isolate also presents with the novel toxin MakA, to our knowledge this is the first reported case from a strain of Asian origin. The MakA (motility associated killing factor $\mathrm{A}$ ) is a flagella-mediated toxin secreted via the fT3SS. It was first described in 2018 as pathogenic in Caenorhabditis elegans and zebrafish later reported from Tanzania in reservoirs of Vibrio cholera 01 strains and from epidemics occurring 2015 - 2017 and also found in sequenced strains from Uganda 01 cholera outbreaks 2014 - 2016 (55-58). We conclude that the combination of virulence factors of our isolate suggests the finding of a rough variant of a nontoxigenic Vibrio cholerae 0139 rather than a 022 serogroup version (Figure 2). Our ambition to more advanced serotyping and genetic analysis with phylogeny in a Japanesee laboratory has failed due to European regulations (GDPR, General Data Protection Analysis) which has restricted an export of our isolate. Due to the limited number of publications on aquatic and reported clinical cases of Vibrio cholerae 0139 in Vietnam we have not been able to perform a critical review on the genetic properties of the reported isolate (59). The importance of intensified reporting from Asia is reflected in findings that molecular strain changes during the 7th pandemic seem to evolve in South Asian regions and current reporting from the region are scarce and delayed (60-62).

\section{Declarations}

\section{Acknowledgments}


None.

\section{References}

1. Greenberg, A. E. Survival of enteric organisms in seawater. 1956. Public Health Rep. 71:77-86.

2. Hood MA, Ness GE. Survival of Vibrio cholerae and escherichia coli in estuarine waters and sediments. Applied and Environmental Microbiology Mar 1982, 43 (3) 578-584.

https://doi.org/10.1128/aem.43.3.578-584.1982

3. Reen, F., Almagro-Moreno, S., Ussery, D. et al. The genomic code: inferring Vibrionaceae niche specialization. Nat Rev Microbiol 4, 697-704 (2006). https://doi.org/10.1038/nrmicro1476

4. Pacini F. Osservazioni microscopiche e deduzioni patologiche sul cholera asiatico. (Microscopic observations and pathological deductions on Asiatic cholera) Memoria del dott. Filippo Pacini ...: letta alla Societa medico-fisica di Firenze nella seduta del 10 Dicembre 1854. Firenze: Tip. Federigo Bencini, 1854. (Estr. da: Gazzetta medica italiana, Toscana, (1854), p 397 e 405). Pag. 1/30. Biblioteca del Archigimnasio. (Italian)

5. Snow, J. "On the Mode of Communication of Cholera," London: Pamphlet August/September 1849a

6. Gardner AD, Venkatraman KV. The Antigens of the Cholera Group of Vibrios. J Hyg (Lond). 1935 May;35(2):262-82. https://doi.org/10.1017/s0022172400032265

7. Shimada T, Arakawa E, Itoh K, Okitsu T, Matsushima A, Asai Y et al. Extended serotyping schema for Vibrio cholerae. Current Microbiology, Vol. 28 (1994), pp 175-178. https://doi.org/10.1007/BF01571061

8. Yamai S, Okitsu T, Shimada T, Katsube Y. Distribution of Serogroups of Vibrio cholerae non-01 non0139 With Specific Reference to Their Ability to Produce Cholera Toxin, and Addition of Novel Serogroups. The Journal of the Japanese Association for Infectious Diseases. 1997;71(10):1037-1045. https://doi.org/10.11150/kansenshogakuzasshi1970.71.1037

9. Koch R. Der zweite Bericht der deutschen cholera-commission. Dtsch Med Wochenschr. 1883; 9: 743. (German)

10. Kabeshima, T. Immunological properties upon types of cholera bacillus. C.R. Soc. Biol., Paris. (1918) $81,618$.

11. Nobechi, K. Immunological studies upon types of Vibrio cholerae. Sci. Rep. Inst. infect. Dis., Tokyo. (1923) 2, 43.

12. Chastel C. Le centenaire de la decouverte du vibrion d'El Tor (1905) ou les debuts incertains de la septieme pandemie du cholera (The century of the discovery of the vibrio El Tor (1905) or dubious 
beginnings of the seventh pandemic of cholera) (French). Histoire des sciences medicales (2007) 41(1):71-82.

13. Hu D, Liu B, Feng L, Ding P, Guo X, Wang M et al. Origins of the current seventh cholera pandemic. Proc Natl Acad Sci U S A. 2016;113(48):E7730-E7739.

https://doi.org/10.1073/pnas.1608732113

14. Gotschlich F. Uber Cholera and cholerazhnliche Vibrioen unter den aus Mekka zuriickkehrenden Pilgern. (1906) Z Hyg Infektionskr 53:281-304. (German)

15. Koch R. An address on cholera and its bacillus. BMJ. 1884; 2: 453-459. https://doi.org/10.1136/bmj.2.1236.453

16. De SN. Enterotoxicity of bacteria-free culture-filtrate of Vibrio cholerae. Nature. 1959;183(4674):15331534. https://doi.org/10.1038/1831533a0

17. Dutta NK, Panse MV, Kulkarni DR. Role of cholera toxin in experimental cholera. Journal of Bacteriology, 1959;78:594_595. https://doi.org/10.1128/jb.78.4.594-595.1959

18. Clemens JD, Nair GB, Ahmed T, Qadri F, Holmgren J. Cholera. Lancet. 2017;390(10101):1539-1549. https://doi.org/10.1016/s0140-6736(17)30559-7

18. Waldor MK, Mekalanos JJ. Lysogenic conversion by a filamentous phage encoding cholera toxin. Science. 1996 Jun 28;272(5270):1910-4. https://doi.org/10.1126/science.272.5270.1910

20. Albert MJ, Siddique AK, Islam MS, Faruque AS, Ansaruzzaman M, Faruque SM et al. Large outbreak of clinical cholera due to Vibrio cholerae non-01 in Bangladesh. Lancet. 1993;341(8846):704. https://doi.org/10.1016/0140-6736(93)90481-u

21. Ramamurthy T, Garg S, Sharma R, Bhattacharya SK, Nair GB, Shimada T et al. Emergence of novel strain of Vibrio cholerae with epidemic potential in southern and eastern India. Lancet. 1993;341(8846):703-704. https://doi.org/10.1016/0140-6736(93)90480-5

22. Li B, Xiao Y, Wang D, Tan H, Ke D, He D et al. Genetic relatedness of selected clinical Vibrio cholerae 0139 isolates from the southern coastal area of China over a 20-year period. Epidemiology and Infection, 2016 Sep;144(12): 2679-2687. https://doi.org/10.1017/s0950268816001059

23. David P. Clark, Nanette J. Pazdernik, in Molecular Biology (Second Edition), 2013

24. Mitra R, Basu A, Dutta D, Nair GB, Takeda Y. Resurgence of Vibrio cholerae 0139 Bengal with altered antibiogram in Calcutta, India. Lancet. 1996;348(9035):1181. https://doi.org/10.1016/s01406736(05)65326-3 
25. Sharma C, Maiti S, Mukhopadhyay A, Basu A, Basu I, Nair GB et al. Unique organization of the CTX genetic element in Vibrio cholerae 0139 strains which reemerged in Calcutta, India, in September 1996. J Clin Microbiol. (1997);35(12):3348-3350. https://doi.org/10.1128/jcm.35.12.3348-3350.1997

26. Mutreja A, Kim DW, Thomson NR, Connor TR, Lee JH, Kariuki S et al. Evidence for several waves of global transmission in the seventh cholera pandemic. Nature. 2011;477(7365):462-465.

https://doi.org/10.1038/nature10392

27. Banerjee R, Das B, Nair GB, Basak S. Dynamics in genome evolution of Vibrio cholerae. Infect Genet Evol. 2014;23:32-41. https://doi.org/10.1016/j.meegid.2014.01.006

28. Deshayes S, Daurel C, Cattoir V, Parienti J-J, Quilici M-L, de La Blanchardière A. Non-01, non-0139 Vibrio cholerae bacteraemia: case report and literature review. SpringerPlus (2015) 4:575. https://doi.org/10.1186/s40064-015-1346-3

29. Bagchi K, Echeverria P, Arthur JD, Sethabutr O, Serichantalergs O, Hoge CW. Epidemic of diarrhea caused by Vibrio cholerae non-01 that produced heat-stable toxin among Khmers in a camp in Thailand. J Clin Microbiol. 1993;31(5):1315-1317. https://doi.org/10.1128/jcm.31.5.1315-1317.1993

30. Chatterjee S, Ghosh K, Raychoudhuri A, Chowdhury G, Bhattacharya MK, Mukhopadhyay AK et al. Incidence, virulence factors, and clonality among clinical strains of non-01, non-0139 Vibrio cholerae isolates from hospitalized diarrheal patients in Kolkata, India. J Clin Microbiol. 2009; 47(4):1087-1095. https://doi.org/10.1128/jcm.02026-08

31. Hwang S, Kim Y, Jung H, Chang HH, Kim SJ, Park HK et al. A Fatal Case of Bacteremia Caused by Vibrio cholerae Non-01/0139. Infect Chemother. 2021 Jun;53(2):384-390.

https://doi.org/10.3947/ic.2020.0301

32. Li Z, Lu X, Wang D, Liang WL, Zhang J, Li J, Xu J, Pang B, Kan B. Genomic comparison of serogroups 0159 and 0170 with other Vibrio cholerae serogroups. BMC Genomics. 2019;20(1):241. https://doi.org/10.1186/s12864-019-5603-7

33. Lan NP, Nga TV, Yen NT, Dung I, Tuyen HT, Campbell Jl et al. Two cases of bacteriemia caused by nontoxigenic, non-01, non-0139 Vibrio cholerae isolates in Ho Chi Minh City, Vietnam. J Clin Microbiol. 2014;52(10):3819-3821. https://doi.org/10.1128/jcm.01915-14

34. Diep TT, Nguyen NT, Nguyen TN, An HK, Nguyen TQ, Nguyen VH et al. Isolation of New Delhi metalloB-lactamase 1-producing Vibrio cholerae non-01, non-0139 strain carrying ctxA, st and hly genes in southern Vietnam. Microbiol Immunol. 2015;59(5):262-267. https://doi.org/10.1111/1348-0421.12248

35. Chen H, Liu K, Li Z, Wang P. Point of care testing for infectious diseases. Clin Chim Acta. 2019;493:138-147. https://doi.org/10.1016/j.cca.2019.03.008 
36. Silbert S, Gostnell A, Kubasek C, Widen R. Evaluation of the new FecalSwab system for maintaining stability of stool samples submitted for molecular tests. J Clin Microbiol (2017) 55:1588-1590. https://doi.org/10.1128/jcm.00273-17

\section{BioFire Gastrointestinal Panel Instruction Booklet}

38. Ramamurthy, Thandavarayan \& Bhattacharya, S.K.. (2011). Epidemiological and Molecular Aspects on Cholera. Humana Press, Totowa, NJ, United States. pp 140-141.

39. Yamasaki S, Shimizu T, Hoshino K, Ho ST, Shimada T, Nair GB, Takeda Y. The genes responsible for Oantigen synthesis of Vibrio cholerae 0139 are closely related to those of vibrio cholerae 022. Gene. 1999 Sep 17;237(2):321-32. https://doi.org/10.1016/s0378-1119(99)00344-3

40. Faruque SM, Sack DA, Sack RB, Colwell RR, Takeda Y, Nair GB. Emergence and evolution of Vibrio cholerae 0139. Proc Natl Acad Sci U S A. 2003;100(3):1304-1309.

https://doi.org/10.1073/pnas.0337468100

41. Ramamurthy T, Mutreja A, Weill F-X, Das B, Ghosh A, Nair GB. Revisiting the global epidemiology of cholera in conjunction with the genomics of Vibrio cholerae. Front. Public Health 2019;7:203. https://doi.org/10.3389/fpubh.2019.00237

42. Siddique AK, Akram K, Zaman K, Mutsuddy P, Eusof A, Sack RB. Vibrio cholerae 0139: How great is the threat of a pandemic? Trop Med Int Health. 1996;1(3):393-398. https://doi.org/10.1046/j.13653156.1996.d01-54.x

43. Dalsgaard A, Mazur J, Dalsgaard I. Misidentification of Vibrio cholerae 0155 isolated from imported shrimp as 0 serogroup 0139 due to cross-agglutination with commercial 0139 antisera. J Food Prot. 2002 Apr;65(4):670-2. https://doi.org/10.4315/0362-028x-65.4.670

44. Mitra RK, Nandy RK, Ramamurthy T, Bhattacharya SK, Yamasaki S, Shimada T et al. Molecular characterisation of rough variants of Vibrio cholerae isolated from hospitalised patients with diarrhoea. $J$ Med Microbiol. 2001 Mar;50(3):268-276. https://doi.org/10.1099/0022-1317-50-3-268

45. Hu D, Yin Z, Yuan C, Yang P, Qian C, Wei Y et al. Changing molecular epidemiology of Vibrio cholerae outbreaks in Shanghai, China. mSystems 2019;4(6)e00561-19.

https://doi.org/10.1128/msystems.00561-19

46. Dorman MJ, Domman D, Uddin MI et al. High quality reference genomes for toxigenic and nontoxigenic Vibrio cholerae serogroup 0139. Sci Rep. 2019;9(1):5865. https://doi.org/10.1038/s41598-01941883-x

47. Dziejman M, Balon E, Boyd D, Fraser CM, Heidelberg JF, Mekalanos JJ. Comparative genomic analysis of Vibrio cholerae: genes that correlate with cholera endemic and pandemic disease. Proc Natl Acad Sci U S A. 2002;99(3):1556-1561. https://doi.org/10.1073/pnas.042667999 
48. O'Shea YA, Finnan S, Reen FJ, Morrissey JP, O'Gara F, Boyd EF. The Vibrio seventh pandemic island-II is a $26.9 \mathrm{~kb}$ genomic island present in Vibrio cholerae El Tor and 0139 serogroup isolates that shows homology to a $43.4 \mathrm{~kb}$ genomic island in V. vulnificus. Microbiology. 2004;150(Pt 12):4053-4063. https://doi.org/10.1099/mic.0.27172-0

49. Siriphap A, Leekitcharoenphon P, Kaas RS, Theethakaew C, Aarestrup FM, Sutheinkul O et al. Characterization and genetic variation of Vibrio cholerae isolated from clinical and environmental sources in Thailand. PLoS One 2017;12(1):e0169324. https://doi.org/10.1371/journal.pone.0169324

50. Haley BJ, Choi SY, Grim CJ, Onifade TJ, Cinar HN, Tall BD et al. Genomic and phenotypic characterization of Vibrio cholerae non-01 isolates from a US Gulf Coast cholera outbreak. PLoS One. 2014;9(4):e86264. https://doi.org/10.1371/journal.pone.0086264

51. Imamura D, Morita M, Sekizuka T, Mizuno T, Takemura T, Yamashiro T et al. Comparative genome analysis of VSP-II and SNPs reveals heterogenic variation in contemporary strains of Vibrio cholerae 01 isolated from cholera patients in Kolkata, India. PLoS Negl Trop Dis. 2017;11(2):e0005386.

https://doi.org/10.1371/journal.pntd.0005386

52. Rahman MH, Biswas K, Hossain MA, Sack RB, Mekalanos JJ, Faruque SM. Distribution of genes for virulence and ecological fitness among diverse Vibrio cholerae population in a cholera endemic area: tracking the evolution of pathogenic strains. DNA Cell Biol. 2008;27(7):347-355. https://doi.org/10.1089/dna.2008.0737

53. Satchell KJ. Structure and function of MARTX toxins and other large repetitive RTX proteins. Annu Rev Microbiol. 2011;65:71-90.

https://doi.org/10.1146/annurev-micro-090110-102943

54. Dongre M, Singh B, Aung KM, Larsson P, Miftakhova R, Persson K et al. Flagella-mediated secretion of a novel Vibrio cholerae cytotoxin affecting both vertebrate and invertebrate hosts. Commun Biol. 2018;1:59. https://doi.org/10.1038/s42003-018-0065-z

55. Hounmanou Y, Leekitcharoenphon P, Hendriksen RS, Dougnon TV, Mdegela RH, Olsen JE et al. Surveillance and Genomics of Toxigenic Vibrio cholerae 01 From Fish, Phytoplankton and Water in Lake Victoria, Tanzania. [published correction appears in Front Microbiol. 2019 Dec 20;10:2974]. Front Microbiol. 2019;10:901. https://doi.org/10.3389/fmicb.2019.02974

56. Hounmanou Y, Leekitcharoenphon P, Kudirkiene E, Mdegela RH, Hendriksen RS, Olsen JE et al. Genomic insights into Vibrio cholerae 01 responsible for cholera epidemics in Tanzania between 1993 and 2017. PLoS Negl Trop Dis. 2019;13(12):e0007934. https://doi.org/10.1371/journal.pntd.0007934

57. Aruhomukama D, Sserwadda I, Mboowa G. Whole-genome sequence analysis of Vibrio cholerae from three outbreaks in Uganda, 2014 - 2016. F1000Research 2019, 8:1340. 
https://doi.org/10.12688/f1000research.20048.1

58. Nguyen DT, Ngo TC, Tran HH, Le TH, Nguyen HT, Nguyen BM et al. Characterization of Vibrio cholerae 0139 of an Aquatic Isolate in Northern Vietnam. Open Microbiol J. 2012;6:14-21.

https://dx.doi.org/10.2174\%2F1874285801206010014

59. WHO. Weekly epidemiological record, No 38, 21 September 2018.

https:/apps.who.int/iris/bitstream/handle/10665/274654/WER9338.pdf?ua=1

(accessed Nobember 01, 2021)

60. WHO. Cholera. World Health Organization fact sheet (2017), https://www.who.int/en/news-room/factsheets/detail/cholera

(accessed November 01, 2021)

61. Morita M, Okada K, Yamashiro T, Sekizuka T, Roobthaisong A, Wongboot W et al. Phylogenetic Analysis Revealed the Dissemination of Closely Related Epidemic Vibrio cholerae 01 Isolates in Laos, Thailand, and Vietnam. Open Forum Infect Dis. 2020 Oct 16;7(11). https://doi.org/10.1093/ofid/ofaa492

62. Bhandari M, Jennison AV, Rathnayake IU, Huygens F. Evolution, distribution and genetics of atypical Vibrio cholerae - A review. Infect Genet Evol. 2021 Apr;89:104726.

https://doi.org/10.1016/j.meegid.2021.104726

\section{Figures}




\section{Horizontal gene transfer}

\section{4 different ways for bacterial and archaeal species to share genetic material "sideways"}

\section{Transformation}

\section{Transduction}

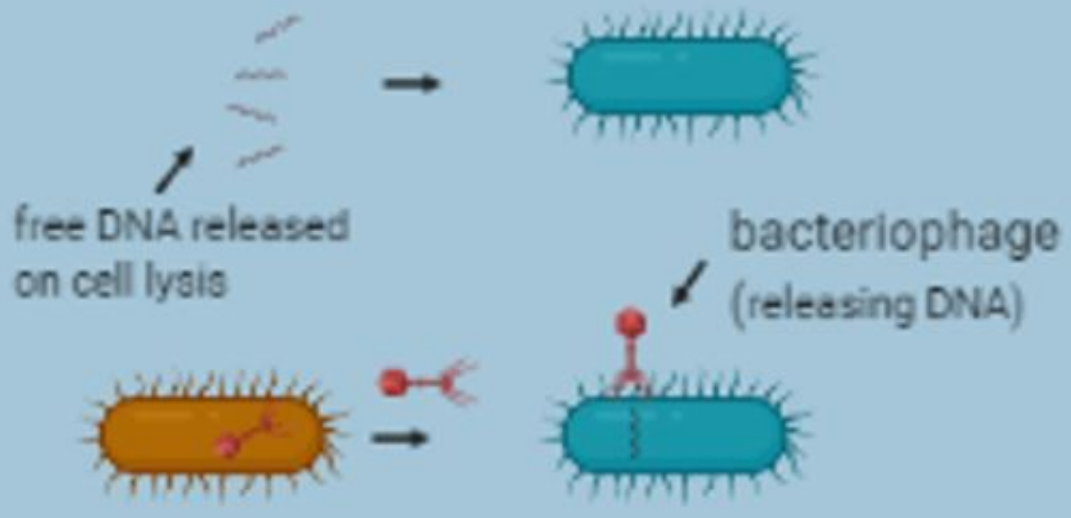

Conjugation

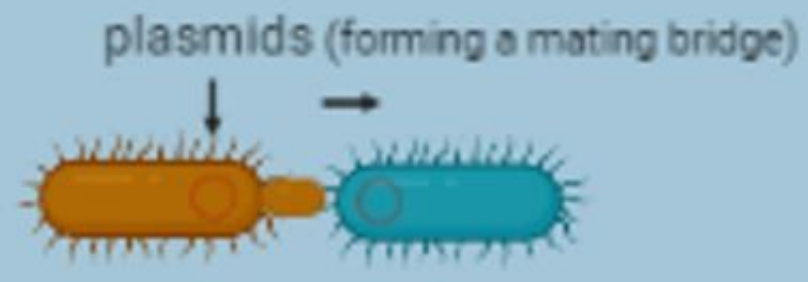

donor

recipient

Gene transfer agents

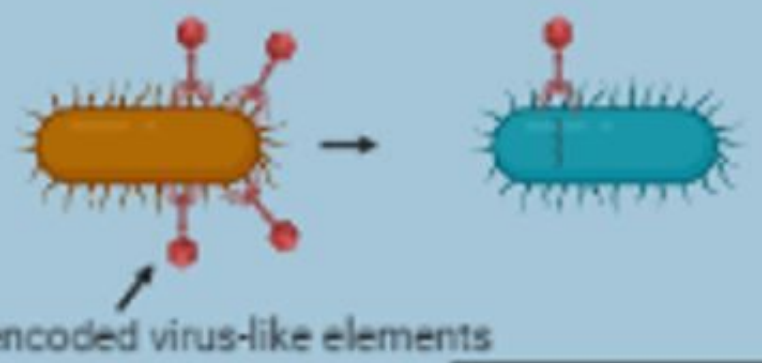

Created in BioRender.com bio

\section{Figure 1}

Horizontal gene transfer. Evolution of bacteria and archaeal species through horizontal gene transfer (or lateral gene transfer) means genetic material being transferred "sideways" instead of evolutionary vertical. It is seen within different variants of a species but also between neighboring species, as we describe in the case of Caenorhabditis elegans to Vibrio cholerae. There are three "classical mechanisms and a fourth hybrid (between transduction and transformation). Recently a fifth mechanism named 
"transfection" has been introduced, but since it is artifically applied in laboratories i.e. with CRISPR/Cas9 technology it is not discussed in this article.

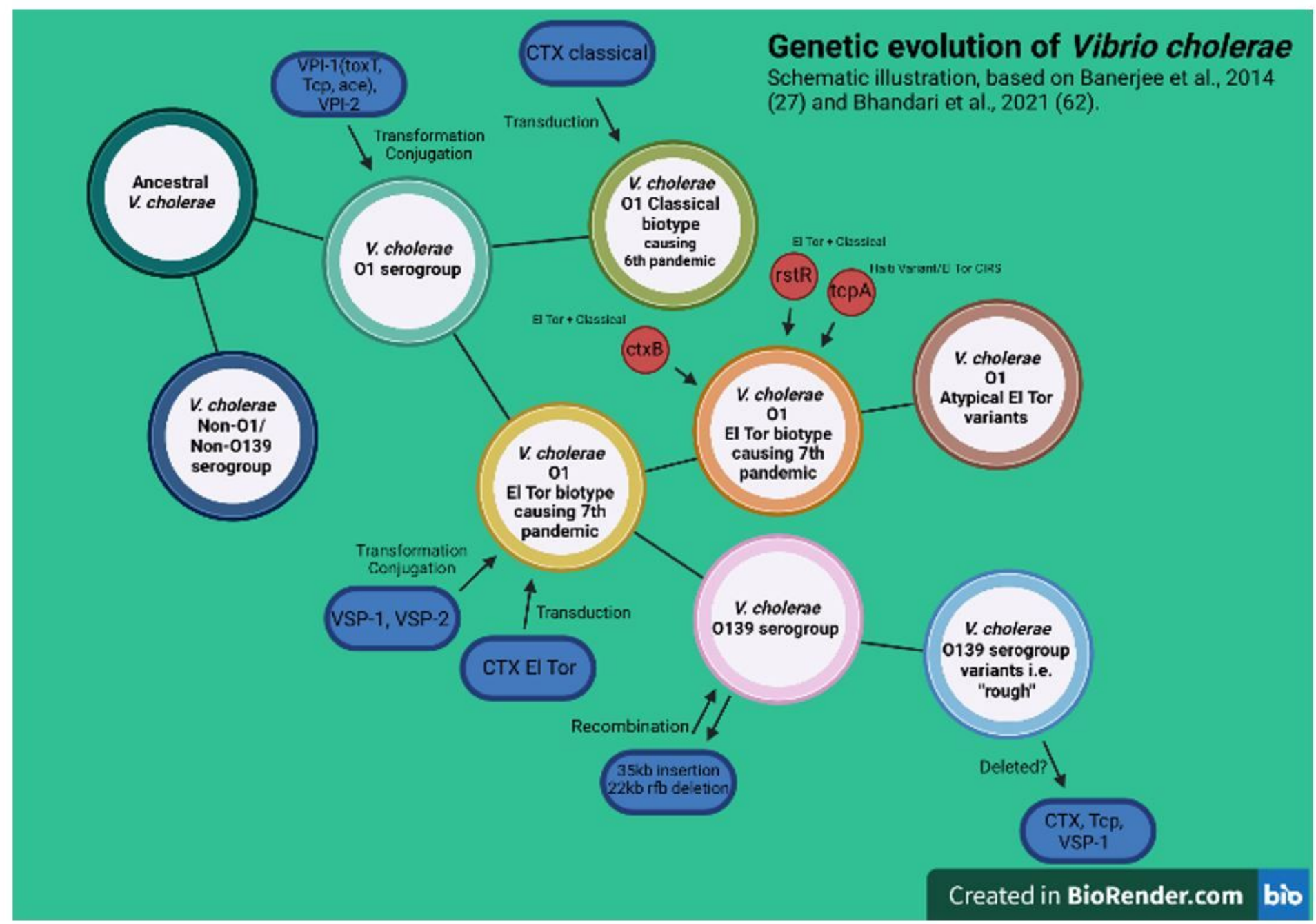

\section{Figure 2}

Schematic illustration of the Vibrio cholerae genetic evolution. The evolutionary pathway from an ancestral Vibrio cholerae strain towards the current 7th pandemic strain involves "milestone" genetic changes in virulent potency, reflecting the characteristics of a newly evolved strain in combination with the immunologic preparedness in the surrounding human population. Vibrio cholerae is prone to genetic change and analysis of historic events by horizontal gene transfer and recombination reveal the chronological pattern of virulence mechanisms. The plastic and genetically diverse pathway involves variant strains with shifting pathogenic potency. We report on a clinical Vibrio cholerae isolate where we have performed whole genome sequencing and found a rare 0139 nontoxigenic rough variant imported to Denmark from Vietnam. 